\title{
SPATIO-TEMPORAL CHANGES OF NET PRIMARY PRODUCTIVITY AND ITS RESPONSE TO PHENOLOGY IN NORTHEAST CHINA DURING 2000-2015
}

\author{
QIU Yue ${ }^{1}$, ZHANG Liguo ${ }^{2}$, FAN Deqin ${ }^{1, *}$ \\ ${ }^{1}$ College of Geoscience and Surveying Engineering, China University of Mining and Technology (Beijing), Beijing 100083, China - \\ qiuyue1993@hotmail.com, kinly129@163.com \\ ${ }^{2}$ Shandong Provincial Institute of Land Surveying and Mapping, Shandong Jinan 250102, China - zlgrh@126.com
}

Commission III, ICWG III/IVe

KEY WORDS: Northeast China, NDVI, Net Primary Productivity, Phenology, Spatio-temporal Changes

\begin{abstract}
:
The relationship between net primary productivity (NPP) and phenological changes is of great significance to the study of regional ecosystem processes. In this study, firstly, NPP was estimated with the remote sensing model based on the SPOT-VGT NDVI dataset (2000-2015), meteorological data and the vegetation map in Northeast China. Then, using NDVI time series data which was reconstructed by polynomial fitting, phenology was extracted with the dynamic threshold method. Finally, the relationship between NPP and phenology was analyzed. The results showed that NPP mainly increased in the cropland, grassland, forestland and shrubland; however, vegetation NPP decreased in the ecotone among cropland, grassland and forestland. Correlation analysis suggested that the relationships between NPP and phenological metrics (i.e., the start of the growing season (SOS), the end of the growing season (EOS), the length of the growing season (LOS)) were different due to geographical location. On the whole, there was a positive correlation between NPP and the LOS in the forestland, and negative in the cropland and grassland, indicating that extended LOS can promote the accumulation of forestland NPP. By analyzing the monthly NDVI data during the vigorous growth period, the increase of NPP in the grassland and cropland was mainly due to the better growth from June to August, and shortened LOS did not lead to reduce the NPP. Generally, the response of NPP to phenology in Northeast China were more complex, showing obvious difference of vegetation types and spatial variability, we need to consider topography, community structure and other factors in the further studies.
\end{abstract}

\section{INTRODUCTION}

Net primary productivity refers to the amount of organic matter accumulated in unit time and area, which can characterize the quality of regional ecosystems and plays an important role in the study of global change and carbon balance (Badeck et al., 2004; Nayak et al., 2010). Phenology is a periodic natural phenomenon in which life activities such as growth and reproduction of plants and animals are affected by the environment (Ruimy et al.,1994). With global warming, the phenology of vegetation has changed (Schwartz et al., 2006), it may lead to changes in vegetation productivity, community composition and structure, as well as water and heat \& $\mathrm{CO}_{2}$ exchange (Piao et al., 2008; Dragoni et al, 2011). Therefore, the research on the relationship between NPP and vegetation phenology is of great significance to the analysis of the impact of phenological changes on the ecosystem processes.

Up to now, some studies have been conducted to explore the relationship between ecological processes and phenology. Based on the MODIS NDVI data (2002-2012) and meteorological data, Yang et al. (2015) found that the LOS extended $0.3 \mathrm{~d} / \mathrm{a}$ and the NPP increased $1.494 \mathrm{gC} \cdot \mathrm{m}^{-2} \cdot \mathrm{a}^{-1}$ significantly in the Tibet Plateau. Using 187 site-years of flux data, $\mathrm{Wu}$ et al. (2012) analyzed spatial and interannual relationships between phenological metrics and annual net ecosystem production (NEP) of three plant functional types in North America, the result suggested that longer LOS can contribute to the increase in annual carbon sequestration and an extra day of LOS would enhance NEP by $3.5 \mathrm{gC} \cdot \mathrm{m}^{-2} \cdot \mathrm{a}^{-1}$, $6.8 \mathrm{gC} \cdot \mathrm{m}^{-2} \cdot \mathrm{a}^{-1}$, and $18.4 \mathrm{gC} \cdot \mathrm{m}^{-2} \cdot \mathrm{a}^{-1}$ for evergreen forests, deciduous forests and non-forest ecosystems respectively. In the boreal and arctic regions, Park et al. (2016) evaluated the effect of phenological changes on gross primary productivity (GPP) based on GIMMS NDVI3g datasets (1982-2014) and pointed out that $42 \%$ of vegetation got a $20.9 \%$ gain in productivity due to the greening trend. Buermann et al. (2013) used GIMMS NDVIg datasets (1982-2008), climate data and microwave data to explore the effect of earlier springs on the ecosystem productivity in the North American boreal forests, the result indicated that ecosystem productivity gained from earlier springs was effectively cancelled out by corresponding losses during the late growing season because of summer droughts. Using FLUXNET data, Falge et al. (2002) observed seasonal variations of GPP in different vegetation functional areas, and found that with the LOS extended by one day, the NEP decreased $2.46 \mathrm{gC} \cdot \mathrm{m}^{-2} \cdot \mathrm{a}^{-1}$ in the grassland. Dunn et al. (2007) investigated the relationship between phenological changes and carbon budget through observational records from 1994 to 2004 in a boreal black spruce forest, the result showed that there was no correlation between longer growing seasons and net uptake. In summary, the relationship between ecosystem productivity and vegetation phenology was complex, including positive correlation, negative correlation and no correlation. The response of vegetation productivity to phenological changes may be different due to various factors, such as data sources,

* Corresponding author 
vegetation types, heat distribution, soil moisture, community structure, and analytical methods.

With the obvious spatial heterogeneity of environmental factors (e.g., soil, topography, water \& heat ), the Northeast China is rich in vegetation types and sensitive to global climate change (Leng et al., 2007). In addition, a large number of forest resources are distributed in the Greater Khingan Mountains, Lesser Khingan Mountains and Changbai Mountains. At present, researches in Northeast China mainly focus on the temporal and spatial pattern of vegetation NPP (Mao et al., 2012), phenology monitoring (Yu et al., 2006) and variation simulation (Guo et al., 2010), but still lack the exploration on the relationship between vegetation NPP and phenological changes. Therefore, in this study, based on SPOT-VGT NDVI data, meteorological data and the vegetation map, we used the remote sensing model (Zhu et al., 2007) and dynamic threshold method to calculate the NPP value and phenological metrics in Northeast China from 2000 to 2015, respectively. And the response mechanism of NPP to phenological changes was analyzed to provide a reference for exploring the ecological process changes in Northeast China.

\section{DATA AND METHODS}

\subsection{Data}

In this study, the SPOT-VGT NDVI dataset (2000-2015) was provided by Data Center for Resources and Environmental Sciences, Chinese Academy of Sciences (RESDC) (http://www.resdc.cn). The dataset was aggregated into monthly time steps by using Maximum Value Composites (MVC) method. The spatial resolution is $1 \mathrm{~km} \times 1 \mathrm{~km}$. Meteorological data (2000-2015) at 107 sites in Northeast China, derived from the China Meteorological Data Sharing Service System (http://cdc.cma.gov.cn/), including mean monthly temperature, total monthly precipitation and total monthly solar radiation. In order to ensure the consistency of the meteorological data and remote sensing dataset in spatial scale, the interpolation method was used to convert the meteorological data into raster format at $1 \mathrm{~km} \times 1 \mathrm{~km}$ spatial resolution. In this study, all data used Albers Conical Equal Area Projection based on WGS-84. The original vegetation map (i.e., 1:1,000,000 scale vegetation distribution map of China) was compiled by the Editorial Committee for Vegetation Map of China (2001). According to the actual situation and research needs in Northeast China, vegetation types in the map were re-recorded and combined. Spatial distribution of vegetation types was shown in Fig. 1.

\subsection{CASA Model}

In this study, an improved CASA model based remote sensing (Zhu et al.,2007; Potter et al., 1993) was used to evaluate the vegetation NPP, which fully considered the plant growth characteristics and abiotic environmental factors (e.g., water, temperature, and light intensity) that can regulate the plant photosynthesis. In this CASA model, the NPP was calculated from absorbed photosynthetically active radiation (APAR) $\left(\mathrm{MJ} \cdot \mathrm{m}^{-2}\right)$ and the actual light use efficiency $(\varepsilon)\left(\mathrm{gC} \cdot \mathrm{MJ}^{-1}\right)$ (equation (1)).

$$
N P P(x, t)=\operatorname{APAR}(x, t) \times \varepsilon(x, t)
$$

where $x$ is the location of a grid cell, and $t$ is the period when NPP is cumulated, such as a month (Zhu et al., 2006).

\subsection{Extraction of Phenological Metrics}

Using NDVI time series data (2000-2015) which was reconstructed by polynomial fitting, vegetation phenology was extracted with the dynamic threshold method. Here, we selected three phenological metrics to investigate vegetation phenology in Northeast China, namely, SOS, EOS and LOS.

2.3.1 Polynomial Fitting: Because of the effects of cloud, atmosphere, sensor and other factors, the original NDVI time series data may contain some singular values. Polynomial fitting method (Piao et al., 2006), based on the principle of least square method, was used to reconstruct the yearly NDVI time series (equation (2)) and can effectively reduce noise.

$$
N D V I=a_{0}+a_{1} x+a_{2} x^{2}+a_{3} x^{3}+\cdots+a_{n} x^{n}
$$

where $x$ is the Julian days, and $n$ is the degree of a polynomial function $(n=6)$.

2.3.2 Dynamic Threshold Method: The method is simple and easy, and it is one of the common methods in extraction of phenological metrics based on remote sensing (White et al., 1997). The NDVI ratio was given by equation (3)

$$
N D V I_{\text {ratio }}=\frac{N D V I-N D V I_{\min }}{N D V I_{\max }-N D V I_{\min }}
$$

where $N D V I_{\max }$ is the annual maximum NDVI, and $N D V I_{\min }$ is the annual minimum NDVI. After several experiments, we found that it was steady and reliable to use ratio of 0.25 and ratio of 0.5 as the threshold to calculate the SOS and EOS, respectively.

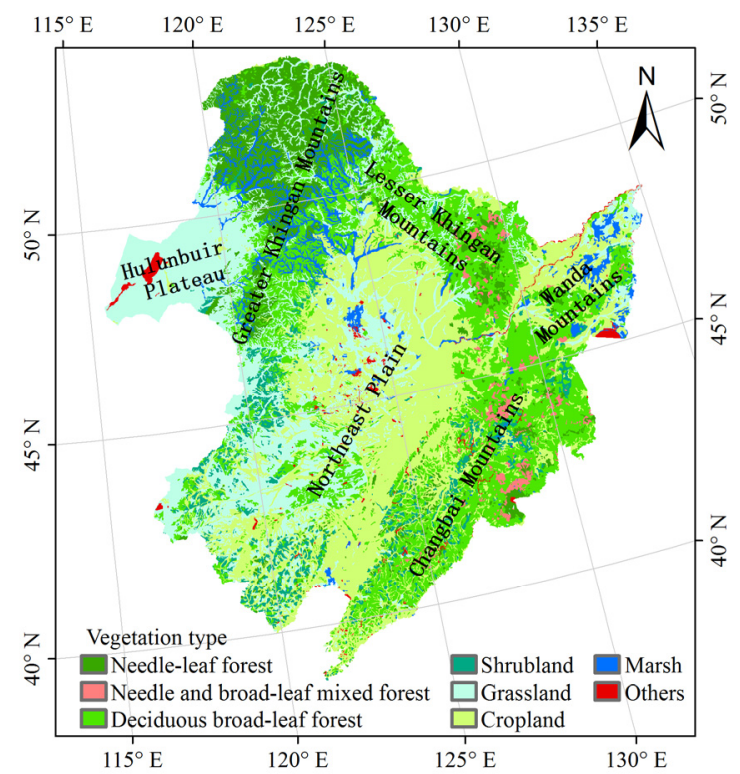

Figure 1. Spatial distribution of vegetation types in Northeast China

\section{RESULTS AND ANALYSES}

\subsection{The Mean Spatial Distribution and Trends of NPP}

The spatial distribution of mean NPP in Northeast China from 2000 to 2015 was consistent with vegetation types, as shown in Fig. 2a. The higher NPP values, ranging from 500 to 
$800 \mathrm{gC} \cdot \mathrm{m}^{-2} \cdot \mathrm{a}^{-1}$, were mainly distributed in humid region of middle temperate zone. The area was abundant in water and heat resources and was suitable for vegetation growth. The main vegetation type was deciduous broad-leaf forest. The medium NPP values ranged from 300 to $500 \mathrm{gC} \cdot \mathrm{m}^{-2} \cdot \mathrm{a}^{-1}$. The main vegetation types were needle-leaf forest, needle $\&$ broadleaf mixed forest, marsh and cropland. Due to a short growth period and small leaves, the productivity of needle-leaf forest was lower than that of deciduous broad-leaf forest in the same study area (Mao et al., 2014). The lower values area mostly existed in semi-arid and semi-humid regions that was not conducive to vegetation growth with less precipitation. The major types of vegetation were grassland and shrubland, less are types of cropland, and the mean NPP ranged from 100 to $300 \mathrm{gC} \cdot \mathrm{m}^{-2} \cdot \mathrm{a}^{-1}$ in this area. The values of NPP under $100 \mathrm{gC} \cdot \mathrm{m}^{-2} \cdot \mathrm{a}^{-1}$ was mainly distributed in ecological fragile areas, such as bare land and desert.

The spatial distribution of trends of NPP in Northeast China from 2000 to 2015 was shown in Fig. 2b. Approximately $69 \%$ of the pixels showed an increasing trend $\left(0 \sim 100 \mathrm{gC} \cdot \mathrm{m}^{-2} \cdot \mathrm{a}^{-1}\right)$, and the main vegetation types were grassland, cropland and forestland (i.e., needle-leaf forest, deciduous broad-leaf forest and needle \& broad-leaf mixed forest). It was noticeable that some forestland of the Changbai Mountains and some cropland of the north of the Northeast Plain had obvious increasing trend (more than $100 \mathrm{gC} \cdot \mathrm{m}^{-2} \cdot \mathrm{a}^{-1}$ ). The above changes may be affected by two aspects: on the one hand, in order to curb the deterioration of the ecological environment, the natural forest protection project had been implemented throughout the country since the late 1990 s, which effectively promoted the protection, cultivation, and development of forest resources, and made NPP increase in the forestland; and on the other hand, with the increase of people's demand for agricultural products and the improvement of agricultural operation and management technology, agriculture had been developing rapidly and the NPP of cropland showed an increasing trend in the Northeast Plain. On the contrary, approximately $31 \%$ of the pixels, which were distributed in the shrubland and the ecotone among cropland, grassland and forestland, showed a decreasing trend $\left(0 \sim 100 \mathrm{gC} \cdot \mathrm{m}^{-2} \cdot \mathrm{a}^{-1}\right)$. This may be resulted from land degradation caused by overgrazing and over-cultivation, and the transformation of land use type.

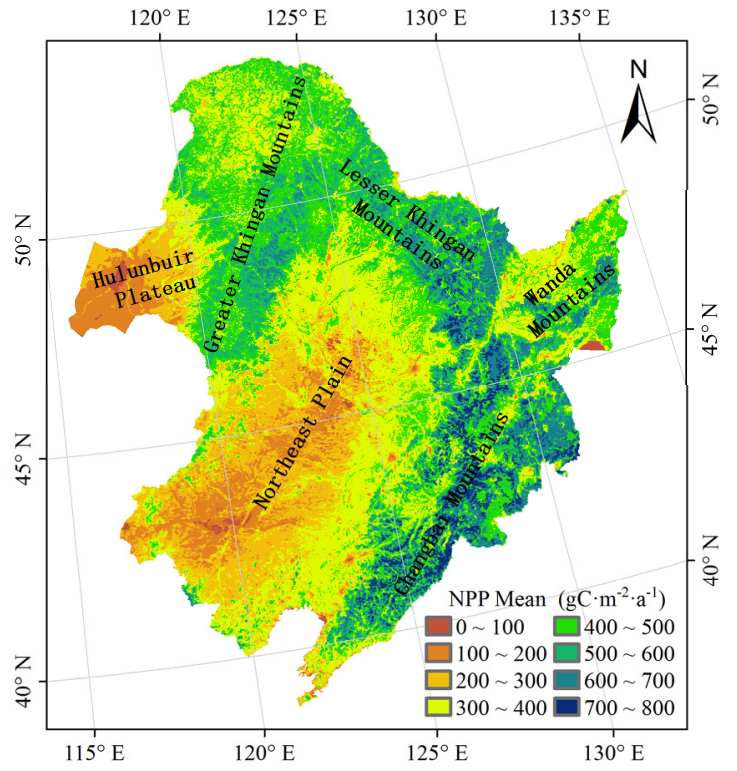

(a) Mean NPP

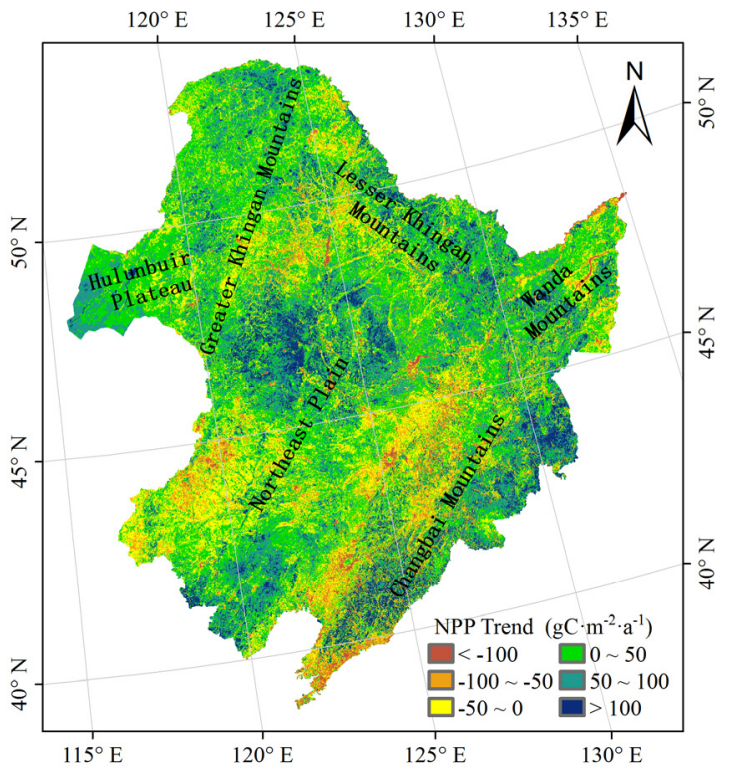

(b) Trend of the NPP

Figure 2. Spatial distribution of mean NPP and change trends in Northeast China from 2000 to 2015

\subsection{The Mean Spatial Distribution and Trends of Vegetation Phenology}

The spatial distribution of the average values of phenological metrics from 2000 to 2015 presented a high spatial heterogeneity in Northeast China (Fig. 3). The attribute of the grid cell is the day of Year (DOY), which refers to the number of days accumulated from January 1 . The SOS mainly occurred between DOY 100 and 160 (i.e., from mid April to early June) in Northeast China (Fig. 3a). There were differences in the SOS for various vegetation types. The earliest SOS, varying from DOY 100 to 110 (i.e., mid April), was mainly located in the most of deciduous broad-leaf forest. The SOS of needle-leaf forest and needle \& broad-leaf mixed forest mainly occurred between DOY 110 and 120 (i.e., late April). The late SOS, ranging from DOY 120 to 160 , was mainly located in the grassland and most of cropland. This area was main grain production and grazing areas in Northeast China, so the SOS was greatly influenced by human activities. From the Fig. 3b, we found that the SOS of forestland in the Greater Khingan Mountains and the northern segment of the Changbai Mountains was in advance (0 10 days) from 2000 to 2015; whereas in the Lesser Khingan Mountains and the southern segment of the Changbai Mountains was delayed (0 10 days). The SOS of cropland was mainly delayed by $0 \sim 20$ days, which may be related to the start time of cultivation. The SOS of most grassland was mainly delayed ( $0 \sim 30$ days), and a small part in the Northeast Plain and the east of Hulunbuir Plateau was in advance (0 20 days).

The mean EOS (during 2000-2015) mainly occurred between DOY 260 and 300 in Northeast China (Fig. 3c). The EOS of most cropland mainly occurred between DOY 270 and 280, that was, early October. It was the time of crops harvesting in the region. The EOS of some forestland in the northern segment of the Greater Khingan Mountains was relatively early and 
occurred between DOY 260 and 270, which may be related to the low temperature and the great temperature difference in autumn. On the contrary, the EOS of some deciduous broad-leaf forest in the southern segment of the Lesser Khingan Mountains and the Changbai Mountains was relatively late and occurred between DOY 280 and 300, which may be related to the humid climate and the small temperature difference in autumn. The EOS of grassland was dispersed, ranging from DOY 260 to 290. The trends of the EOS in Northeast China between 2000 and 2015 was shown in Fig. 3d. The EOS of cropland and grassland was in advance (0 20 days); and the EOS of forestland was delayed (0 20 days), which may be related to the climate warming in Northeast China in recent years (Zhao et al.,2016).

From 2000 to 2015, the LOS of vegetation had a long span in Northeast China, mainly occurred between 100 and 195 days (Fig. 3e). The LOS of grassland was short, mainly occurred between 100 and 150 days. The LOS of part of forestland mainly occurred between 150 and 170 days, which was located in the Greater Khingan Mountains and the northern segment of the Lesser Khingan Mountains; the LOS of other part of forestland was relatively long and mainly occurred between 170 and 195 days, which was located in the Changbai Mountains, the Wanda Mountains and the southern segment of the Lesser Khingan Mountains. From the Fig. 3f, we found that the LOS of grassland and cropland mainly showed shortened trend $(0 \sim 30$ days) and most of forestland showed lengthened trend (0 20 days).

For the phenology of various vegetation types in Northeast China from 2000 to 2015, we can conclude that: 1) in the cropland, the SOS occurred relatively late, the EOS was at an intermediate level, the LOS was shorter and showed a shortening trend; 2) in the grassland, the EOS occurred relatively early, the SOS and LOS were at an intermediate level, and the LOS also showed a shortening trend; 3) in the forestland, the SOS occurred relatively early, the EOS occurred relatively late, and the LOS was longer and showed a lengthening trend.

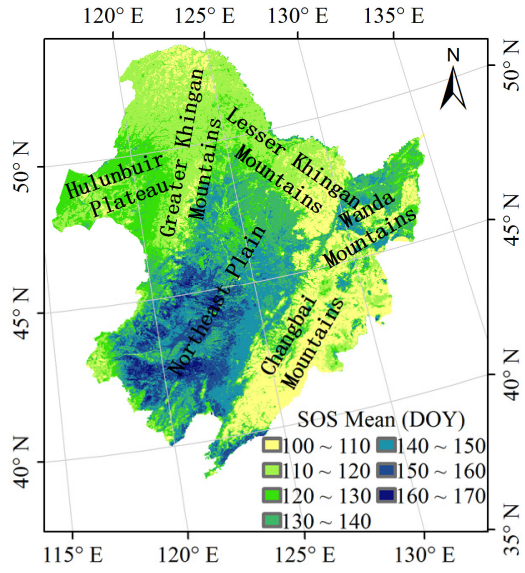

(a) Mean SOS

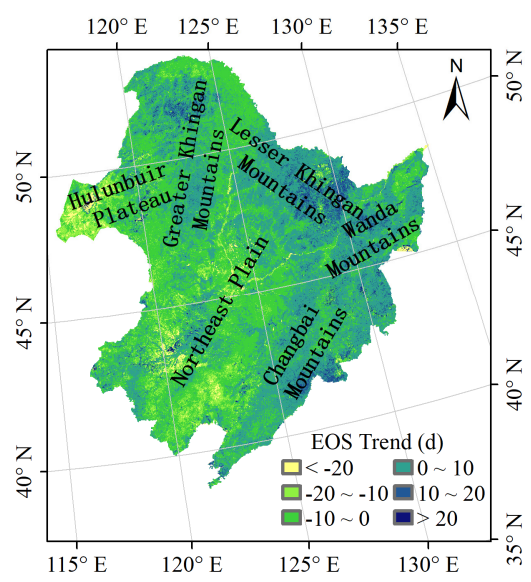

(d) Trend of the EOS

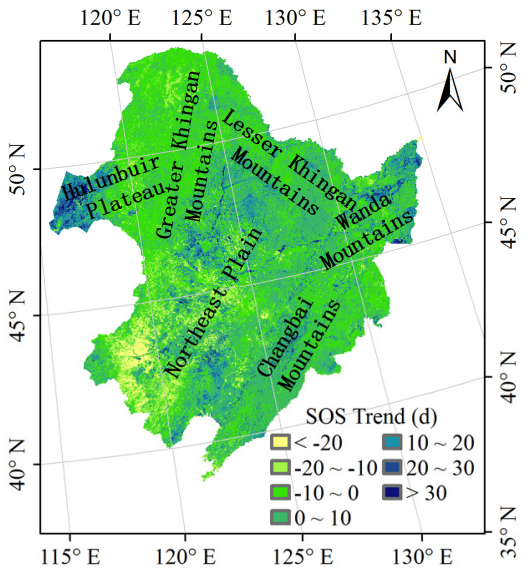

(b) Trend of the SOS

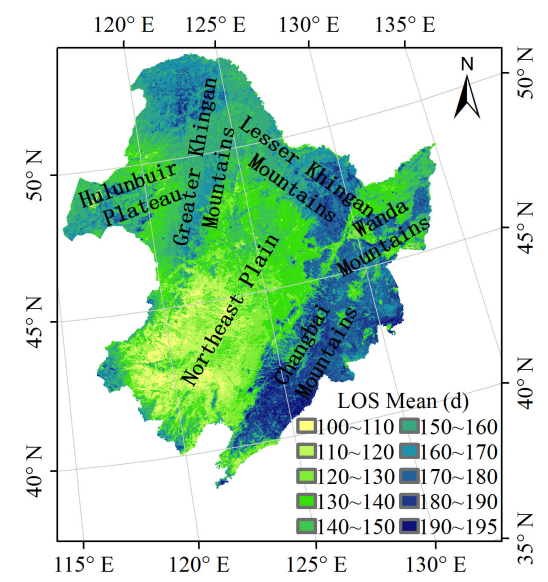

(e) Mean LOS

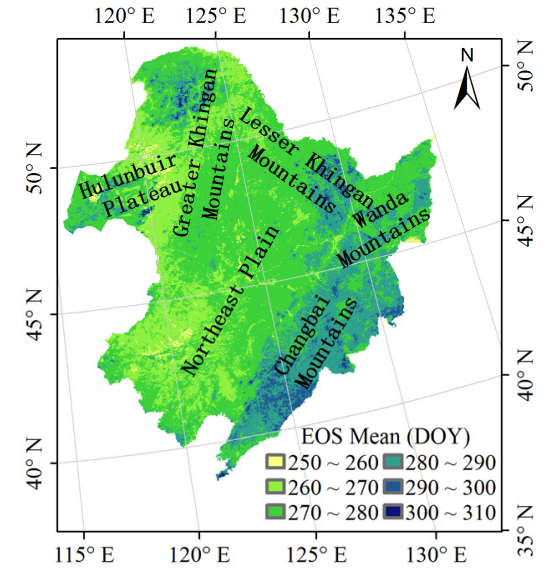

(c) Mean EOS

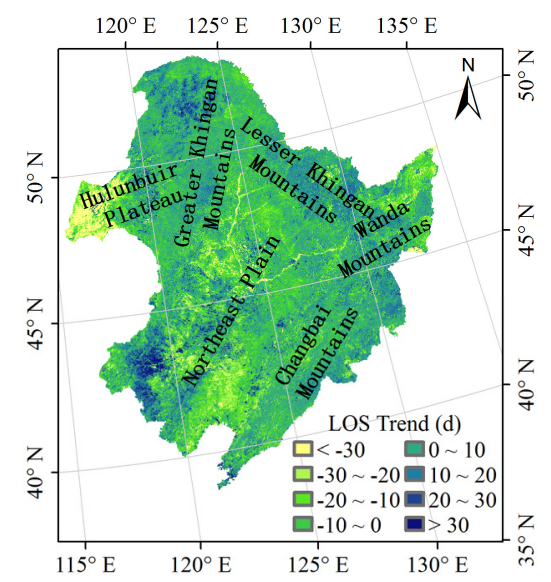

(f) Trend of the LOS

Figure 2. Spatial distribution of phenological metrics and change trends in Northeast China from 2000 to 2015

\subsection{Response of NPP to Phenological Variation}

The results of the correlation analysis $(P<0.05)$ between NPP and phenological metrics (i.e., SOS, EOS and LOS) in Northeast China from 2000 to 2015 showed that the response of vegetation NPP to phenological variation existed differences due to vegetation types and geographical location. On the whole, NPP of needle-leaf forest and SOS was negative correlation, the coefficient was $-0.75 \sim-0.3$. The correlation between NPP of needle-leaf forest and the EOS and the LOS varied with the geographical location. In the northern segment of the Greater Khingan Mountains, the NPP of needle-leaf forest was negatively correlated with the EOS and was not related to the LOS, the coefficient was $-0.65 \sim-0.3$; in the middle segment of the Greater Khingan Mountains, NPP of needle-leaf forest was positively correlated with the EOS and LOS, the correlation 
coefficients were $0.3 \sim 0.65$ and $0.3 \sim 0.7$, respectively; in the southern segment of the Greater Khingan Mountains, NPP of needle-leaf forest was negatively correlated with the EOS and positively correlated with the LOS, the correlation coefficients were $-0.75 \sim-0.3$ and $0.3 \sim 0.65$, respectively. The NPP of deciduous broad-leaf forest was negatively correlated with the SOS and was positively correlated with the LOS, the correlation coefficients were $-0.75 \sim-0.3$ and $0.35 \sim 0.7$, respectively. The correlation between NPP of deciduous broad-leaf forest and the EOS varied with the geographical location. In the Changbai Mountains and the southern segment of the Greater Khingan Mountains, NPP of deciduous broad-leaf forest and EOS was negative correlation, the coefficient was $-0.6 \sim-0.3$; in the Wanda Mountains, the northern segment of the Greater Khingan Mountains and the southern segment of the Lesser Khingan Mountains, NPP of deciduous broad-leaf forest and EOS was positive correlation, the coefficient was $0.3 \sim 0.6$. In the shrubland, the NPP was negatively correlated with the SOS and positively correlated with the LOS, and was not related to the EOS, the correlation coefficients were $-0.75 \sim-0.3$ and $0.3 \sim 0.65$, respectively. The NPP of marsh was negatively correlated with the SOS and positively correlated with the LOS, the correlation coefficients were $-0.75 \sim-0.35$ and $0.3 \sim 0.6$, respectively. In the northern segment of the Greater Khingan Mountains, the NPP of marsh and EOS was positive correlation, the coefficient was $0.3 \sim 0.6$; in the southern segment of the Greater Khingan Mountains, whereas the NPP of marsh and EOS was negative correlation, the coefficient was $-0.7 \sim-0.3$. On the whole, the NPP of grassland was positively correlated with the SOS and negatively correlated with the EOS and the LOS, the correlation coefficients were $0.3 \sim 0.75,-0.8 \sim-0.35$ and -0.8 $\sim-0.35$, respectively. In addition, NPP of grassland which was distributed in the ecotone of grassland and forestland and the ecotone of grassland and cropland was negatively correlated with the SOS and positively correlated with the LOS, the correlation coefficients were $-0.65 \sim-0.3$ and $0.3 \sim 0.6$. The NPP of most cropland was negatively correlated with the SOS, the EOS, and the LOS, respectively, the correlation coefficients were $-0.7 \sim-0.3,-0.65 \sim-0.3$, and $-0.65 \sim-0.3$. Specially, NPP of cropland, which was distributed in the Changbai Mountains and ecotone of cropland and forestland, was positively correlated with the LOS, the coefficient was $0.3 \sim 0.65$. It can be concluded that the response of vegetation NPP to phenology in Northeast China from 2000 to 2015 was more complex, and existed differences due to vegetation types and geographical location.

According to the above statistical analysis results, the Fig. $2 b$ and the Fig. 3f, we found that NPP of vegetation (mainly cropland and grassland) increased with the decreasing LOS in Northeast China from 2000 to 2015. In order to explain this phenomenon, we further analyzed trends of the monthly NDVI data in vigorous growth period (i.e., from June to September) in Northeast China. During 2000-2015, it was found that the monthly NDVI values of cropland and grassland showed an increasing trend and the overall increasing scope was between 0 and 0.2 (more than 0.2 in some areas) in June, July and August; in September, showed a decreasing trend and the overall decreasing scope was between 0 and 0.15 . This indicated that the increase of NPP in cropland and grassland was mainly due to the good growth from June to August, so the shortened LOS did not lead to the decrease of NPP. In the grassland and cropland, the increasing trend of NDVI values may be due to the development of agricultural technology in recent years and the restrictions on grazing.

\section{CONCLUSIONS}

In this study, firstly, NPP was estimated with the remote sensing model based on the SPOT-VGT NDVI dataset (20002015), meteorological data and the vegetation map in Northeast China. Then, using NDVI time series data which was reconstructed by polynomial fitting, phenology was extracted with the dynamic threshold method. Finally, the relationship between NPP and phenology was analyzed. The results showed that the mean NPP ranged from 100 to $800 \mathrm{gC} \cdot \mathrm{m}^{-2} \cdot \mathrm{a}^{-1}$ in Northeast China during 2000 to 2015. The NPP of deciduous broad-leaf forest was the highest, and the mean NPP was between 500 and $800 \mathrm{gC} \cdot \mathrm{m}^{-2} \cdot \mathrm{a}^{-1}$; the NPP of needle-leaf forest, needle \& broad-leaf mixed forest, marsh and most cropland was relatively high, and the mean NPP was between 300 and $500 \mathrm{gC} \cdot \mathrm{m}^{-2} \cdot \mathrm{a}^{-1}$; the NPP of grassland and shrubland was relatively low, and the mean NPP was between 100 and $300 \mathrm{gC} \cdot \mathrm{m}^{-2} \cdot \mathrm{a}^{-1}$. In the grassland, cropland, and forestland, the NPP showed an increasing trend $\left(0 \sim 100 \mathrm{gC} \cdot \mathrm{m}^{-2} \cdot \mathrm{a}^{-1}\right)$; in the shrubland and the ecotone among cropland, grassland and forestland, the NPP showed a decreasing trend $\left(0 \sim 100 \mathrm{gC} \cdot \mathrm{m}^{-2} \cdot \mathrm{a}^{-1}\right)$. For the phenology of various vegetation types, the SOS of cropland occurred relatively late, the EOS was at an intermediate level, the LOS was shorter and showed a shortening trend; the EOS of grassland occurred relatively early, the SOS and LOS were at an intermediate level, and the LOS also showed a shortening trend; the SOS of forestland occurred relatively early, the EOS occurred relatively late, and the LOS was longer and showed a lengthening trend.

Contrary to our expectation, it was found that the NPP was negatively correlated with the LOS in the cropland and grassland. Here, we further analyzed trends of the monthly NDVI data in vigorous growth period, and found that the monthly NDVI values of cropland and grassland showed an increasing trend in June, July and August. This indicated that the increase of NPP in the cropland and grassland was mainly due to the good growth from June to August, so the shortened LOS did not lead to the decrease of NPP.

The results showed that NPP of forestland increased with the extended LOS from 2000 to 2015 in Northeast China, that was, the prolongation of the LOS effectively promoted the accumulation of NPP in forestland. This was basically consistent with findings of the response of forestland NPP to phenology by Dragoni et al. (2011) and Yang et al. (2015). On the contrary, the NPP of cropland and grassland increased with the shortened LOS in Northeast China from 2000 to 2015. It indicated that the response of NPP to phenology in the cropland and grassland was complicated and may be related to the human intervention on agricultural development. In summary, the response of vegetation NPP to phenological changes was complex in Northeast China. In the further studies, the impact of environmental factors (e.g., hydrology, topography, temperature, precipitation, and solar radiation) and natural disasters (e.g., forest fire, flood, and drought) on phenology and vegetation NPP should be fully considered, and the response of vegetation NPP to phenological changes will be deeply analyzed from its mechanism. That can provide the basis for studying the ecological processes, guiding and serving the production of agriculture forest and husbandry, and promoting the sustainable development of ecological economy in Northeast China. 


\section{ACKNOWLEDGEMENTS}

This study was supported by the National Natural Science Foundation of China (NO.41601456).

\section{REFERENCES}

Badeck, F.W., Bondeau, A., Böttcher, K., Doktor, D., Lucht, W., Schaber, J., and Sitch, S., 2004. Responses of spring phenology to climate change. New Phytologist, 162(2), pp. 295309.

Buermann, W., Bikash, P.R., Jung, M., Burn, D.H., and Reichstein, M., 2013. Earlier springs decrease peak summer productivity in North American boreal forests. Environmental Research Letters, 8(2), pp. 024027.

Dragoni, D., Schmid, H.P., Wayson, C.A., Potter, H., Grimmond, C.S., and Randolph, J.C., 2011. Evidence of increased net ecosystem productivity associated with a longer vegetated season in a deciduous forest in south-central Indiana, USA. Global Change Biology, 17(2), pp. 886-897.

Dunn, A.L., Barford, C.C., Wofsy, S.C., Goulden, M.L., and Daube, B.C., 2007. A long-term record of carbon exchange in a boreal black spruce forest: means, responses to interannual variability, and decadal trends. Global Change Biology, 13(3), pp. 577-590.

Editorial Committee for Vegetation Map of China, Chinese Academy of Science, 2001. Vegetation Atlas of China. Science Press, Beijing.

Falge, E., Baldocchi, D., Tenhunen, J., Aubinet, M., Bakwin, P. Berbigier, P., Bernhofer, C., Burba, G., Clement, R., Davis, K.J., Elbers, J.A., Goldstein, A.H., Grelle, A., Granier, A., Guomundsson, J., Hollinger, D., Kowalski, A.S., Katul, G., Law, B.E., Malhi, Y., Meyers, T., Monson, R.K., Munger, J., Oechel, W., Paw, UKT., Pilegaard, K., Rannik, U., Rebmann, C., Suyker, A., Valentini, R., Wilson, K., and Wofsy, S., 2002. Seasonality of ecosystem respiration and gross primary production as derived from FLUXNET measurements. Agricultural and Forest Meteorology, 113(1-4), pp. 53-74.

Guo, Z.X., Zhang, X.N., Wang, Z.M., and Fang, W.H., 2010. Simulation and variation pattern of vegetation phenology in Northeast China based on remote sensing. Chinese Journal of Ecology, 29(1), pp. 165-172.

Leng, W.F., He, H.S., Bu, R.C., and Hu, Y.M., 2007. Sensitivity analysis of the impacts of climate change on potential distribution of three larch (Larix) species in northeastern China. Journal of Plant Ecology (Chinese Version), 31(5), pp. 825-833.

Mao, D.H., Wang, Z.M., Han, J.X., and Ren, C.Y., 2012. Spatio-temporal pattern of net primary productivity and its driven factors in Northeast China in 1982-2010. Scientia Geographica Sinica, 32(9), pp. 1106-1111.

Mao, D.H., Wang, Z.M., Wu, C.S., Song, K.S., and Ren, C.Y., 2014. Examining forest net primary productivity dynamics and driving forces in northeastern China during 1982-2010. Chinese Geographical Science, 24(6), pp. 631-646.
Nayak, R.K., Patel, N.R., and Dadhwal, V.K., 2010. Estimation and analysis of terrestrial net primary productivity over India by remote-sensing-driven terrestrial biosphere model. Environmental Monitoring and Assessment, 170(1-4), pp. 195213.

Park, T., Ganguly, S., Tømmervik, H., Euskirchen, E.S., Høgda, K.A., Karlsen, S.R., Brovkin, V., Nemani, R.R., and Myneni, R.B., 2016. Changes in growing season duration and productivity of northern vegetation inferred from long-term remote sensing data. Environmental Research Letters, 11(8), pp. 084001 .

Piao, S.L., Ciais, P., Friedlingstein, P., Peylin, P., Reichstein, M., Luyssaert, S., Margolis, H., Fang, J.Y., Barr, A., Chen, A.P., Grelle, A., Hollinger, D.Y., Laurila, T., Lindroth, A., Richardson, A.D., and Vesala, T., 2008. Net carbon dioxide losses of northern ecosystems in response to autumn warming. Nature, 451(7174), pp. 49-52.

Piao, S.L., Fang, J.Y., Zhou, L.M., Ciais, P., and Zhu, B., 2006. Variations in satellite-derived phenology in China's temperate vegetation. Global Change Biology, 12(4), pp. 672-685.

Potter, C.S., Randerson, J.T., Field, C.B., Matson, P.A., Vitousek, P.M., Mooney, H.A., and Klooster, S.A., 1993. Terrestrial ecosystem production: A process model based on global satellite and surface data. Global Biogeochemical Cycles, 7(4), pp. 811-841.

Ruimy, A., Saugier, B., and Dedieu, G., 1994. Methodology for the estimation of terrestrial net primary production from remotely sensed data. Journal of Geophysical Research, 99(D3), pp. 5263-5283.

Schwartz, M.D., Ahas, R., and Aasa, A., 2006. Onset of spring starting earlier across the Northern Hemisphere. Global Change Biology, 12(2), pp. 343-351.

White, M.A., Thornton, P.E., and Running, S.W., 1997. A continental phenology model for monitoring vegetation responses to interannual climatic variability. Global Biogeochemical Cycles, 11(2), pp. 217-234.

Wu, C.Y., Gonsamo, A., Chen, J.M., Kurz, W.A., Price, D.T., Lafleur, P.M., Jassal, R.S., Dragoni, D., Bohrer, G., Gough, C.M., Verma, S.B., Suyker, A.E., and Munger, J.W., 2012. Interannual and spatial impacts of phenological transitions, growing season length, and spring and autumn temperatures on carbon sequestration: A North America flux data synthesis. Global and Planetary Change, 92-93(4), pp. 179-190.

Yang, B.J., Wang, S.Y., Chang, Q., Sun, Y.X., Yin, H., and Wang, X.Y., 2015. Response of NPP to phenology changes in the Tibet Plateau. Geography and Geo-Information Science, 31(5), pp. 115-120.

Yu, X.F., and Zhuang, D.F., 2006. Monitoring forest phenophases of Northeast China based on MODIS NDVI data. Resources Science, 28(4), pp. 111-117.

Zhao, J.J., Wang, Y.Y., Zhang, Z.X., Zhang, H.Y., Guo, X.Y., Yu, S., Du, W.L., and Huang, F., 2016. The variations of land surface phenology in Northeast China and its responses to climate change from 1982 to 2013. Remote Sensing, 8(5), pp. 400 . 
Zhu, W.Q., Pan, Y.Z., He, H., Yu, D.Y., and Hu, H.B., 2006. Simulation of maximum light use efficiency for some typical vegetation types in China. Chinese Science Bulletin, 51(4), pp. 457-463.

Zhu, W.Q., Pan, Y.Z., and Zhang, J.S., 2007. Estimation of net primary productivity of Chinese terrestrial vegetation based on remote sensing. Journal of Plant Ecology (formerly Acta Phytoecologica Sinica), 31(3), pp. 413-424. 